\title{
DEMOCRACIA E PARTICIPAÇÃO POLÍTICA: PROBLEMATIZANDO CONCEITOS E CATEGORIAS NA ANÁLISE DAS DEMOCRACIAS LATINO-AMERICANAS
}

\author{
Camila Penna ${ }^{1}$
}

\begin{abstract}
Resumo
0 artigo discute os conceitos de democracia e de participação política a partir de diferentes perspectivas, com vistas a assinalar tanto as limitações como as contribuições de alguns destes conceitos para a análise das democracias latino-americanas. Primeiramente, 0 artigo analisa a literatura sobre transição democrática e democratização e aponta as deficiências do conceito de democracia presente nesta literatura, no que tange à análise de processos históricos da América Latina e de processos mais recentes de mobilização social em vários países. $\mathrm{Na}$ segunda sessão, o trabalho discute a literatura de democracia participativa contrastando-a com as perspectivas minimalistas de democracia. Argumenta-se que os trabalhos a partir destas perspectivas podem levar a análises incompletas e superficiais do processo de construção democrática na América Latina.
\end{abstract}

Palavras-chave: Democracia. Participação política. América Latina. Conceitos.

\footnotetext{
${ }^{1}$ Doutoranda em Ciências Sociais no Centro de Pesquisa e Pós-Graduação sobre as Américas Universidade de Brasília. End. Eletrônico: camilapenna2003@yahoo.com.br
} 


\title{
DEMOCRACY AND POLITICAL PARTICIPATION: QUESTIONING THE VALIDITY OF SOME CONCEPTS AND CATEGORIES TO THE ANALYSIS OF LATIN AMERICAN DEMOCRACIES
}

\begin{abstract}
The article discusses the concepts of democracy and political participation through different perspectives aimed at pointing out the limitations as well as the contributions of some of those concepts for the analysis of Latin-American democracies. In the first section the article analyses democratic transition and democratization literature pointing out the deficiencies of the concept of democracy present in this literature when it comes to the approach of historical Latin American political process and more recent phenomenon of social mobilization in various countries. The second section discusses the participatory democracy literature and contrasts it with a minimalist conception of democracy. We argue that working under this perspective might lead to incomplete and superficial analysis of the Latin American democratization process.
\end{abstract}

Keywords: Democracy. Political participation. Latin America. Concepts.

\section{INTRODUÇÃO}

0 artigo discute os conceitos de democracia e de participação política, com 0 objetivo de identificar as possíveis implicações dos diferentes significados atribuídos a estes termos para a análise das democracias latino-americanas realmente existentes. Para tanto, discute-se, em um primeiro momento, as contribuições da literatura sobre transição democrática e democratização apontando para as deficiências do conceito de democracia utilizado por essa literatura, quando contrastado com processos históricos característicos da América Latina e com processos mais recentes de participação política e mobilização social. Em um segundo momento, discute-se a literatura sobre democracia participativa e participação política, apontando como abordagens que analisam o processo de democratização a partir de uma concepção minimalista de democracia podem levar a análises superficiais e incompletas que não problematizam elementos como desigualdade, pobreza, exclusão social e participação extra-institucional, de relevância central para a consolidação democrática.

A partir desta discussão se questiona a utilidade de determinados conceitos e significados - que vêm sendo utilizados no debate sobre democracia e participação 
política - para a compreensão e interpretação das realidades latino-americanas. Argumenta-se também que uma análise mais detida dos conceitos de participação política e de democracia utilizados não só por agentes do processo político, como também no campo acadêmico, pode ser útil para apreender os diferentes discursos em jogo e as implicações de cada um destes, do ponto de vista de definir quem está autorizado a participar com legitimidade do processo político democrático.

\section{Transitologia, DEMOCRATIZAÇÃo E PARTICIPAÇÃO}

Quando analisamos a utilidade de determinados conceitos e categorias para a compreensão de nossa própria realidade, é relevante a observação da história de construção desses conceitos e de como eles vêm sendo utilizados recentemente. Nesse aspecto podemos destacar as contribuições de alguns autores centrais que estudaram processos de clientelismo, patrimonialismo e particularismo no Brasil. Cabe notar que esses autores identificam e problematizam, desde o início, a incongruência entre nossa realidade e os modelos e instituições da Europa e dos países do norte que nos serviram de "modelo". Há tanto um questionamento relativo à utilidade da aplicação acrítica desses modelos do ponto de vista político prático, ou seja, da medida em que sua adoção contribui ou atrapalha o funcionamento do sistema político; como um questionamento da utilidade dos conceitos e significados inerentes a esses modelos para a compreensão e interpretação de nossa realidade.

A artificialidade da importação de instituições políticas liberais vigentes na Europa para o contexto latino-americano, e, mais especificamente para o Brasil, já era assinalada por historiadores e cientistas sociais estudiosos do processo de formação política brasileira. Essa preocupação está presente em obras tão díspares como as de Oliveira Viannae de Raymundo Faoro. Com efeito, o primeiro argumenta que a implantação do sufrágio universal, pelo Código de Processo de 1832, foi uma medida dissonante do contexto sócio-político brasileiro tendo contribuído apenas para a transformação dos clãs feudais em clãs eleitorais, com ausência de práticas democráticas de fato (VIANNA, 1999). 0 segundo aponta para a sobrevivência e interpenetração da dominação patrimonial à racionalidade burocrática (FA0R0, 1993), processo que, na perspectiva deste autor, teria implicado em uma impossibilidade de implantação do liberalismo político democrático, assim como do liberalismo econômico. Em sociedades cujo tipo de dominação predominante é o patrimonial, o liberalismo político seria nada mais que uma ficção ou uma fachada, uma máscara que conserva privilégios (HOLLANDA apud FAORO, 1993). 
Criticando a adoção do liberalismo político como um modelo e as implicações que esse processo teve para o país, Faoro (1993) recorda Hollanda ao apontar que com a máscara do liberalismo fabricou-se uma "realidade artificiosa e livresca, onde nossa vida verdadeira morria asfixiada."

Em consonância com os elementos presentes nessas análises históricas da formação política do Brasil está nossa primeira crítica à literatura sobre transição e consolidação democrática. Os estudos que se tornaram referência no campo do que ficou conhecido como transitologia e consolidologia² (0'DONNELL; SCHMITTER; WHITEHEAD, 1988; LINZ; STEPAN, 1999), concebem como fim desejável do processo de transição a democracia política, referente ao conceito de poliarquia de Dahl (1997)3. Enfatiza-se, pois, como critérios para a presença de uma democracia a existência de eleições livres e competitivas e o respeito aos direitos individuais e associativos (0'DONNELL, 1986). Mas, a constatação de que instituições políticas características de uma poliarquia - tomando-se como modelo as velhas poliarquias consolidadas da Europa ocidental e dos Estados Unidos seriam o fim desejável para o processo de transição na América Latina implica em alguma artificialidade, tal como a importação do liberalismo político no século XIX, na medida em que se desconsideram processos históricos característicos desses países que vão além do autoritarismo comum a todos eles - processos estes talvez impeditivos da instalação de uma poliarquia nos moldes dos países tomados como exemplo.

Referimo-nos às práticas ou tipos de relação social e política que levam àquilo que 0'Donnell (1997) chama de ofuscamento dos limites e da distinção entre esfera privada e esfera pública, o que iria contra o conceito de poliarquia. 0’Donnell explicita duas dessas práticas, o clientelismo e o particularismo, e utiliza estes termos para se referir a "Tipos de relações não universalísticas, variando de trocas particulares hierárquicas, partonagem, nepotismo e favores, a ações que sob as regras formais do pacote da poliarquia seriam consideradas corruptas (0'DONNELL,1997, p. 49).

\footnotetext{
${ }^{2}$ Termos cunhados por Phillipe Schmitter e utilizados por Vitullo (2006).

${ }^{3}$ Seguindo a linha proposta por Shumpeter (1975) de que o conceito de democracia deveria estar isento de qualquer carga normativa referente aos seus fins (a idéia do bem comum) - devendo se referir unicamente ao método utilizado para se adquirir poder por meio da competição entre partidos -, Dahl define os requerimentos mínimos para falar em democracia ou em poliarquia como ele o define. Esses requerimentos são: "votos secretos, sufrágio universal, eleições regulares, competição partidária, direito de associação e responsabilidade do executivo" (DAHL, 1997, p.27).
} 
A concepção de que a transição democrática de regimes burocráticoautoritários deveria ter como fim a implantação de uma democracia política (O'DONNELL, 1986) ou uma poliarquia (O'DONNELL; SCHMITTER; WHITEHEAD, 1988) gera alguns problemas quando se contrasta esse modelo, tomado como fim, com as democracias latino-americanas realmente existentes (VITULLO, 2006). Em outras palavras, a idéia de que a transição de um regime autoritário levaria minimamente a uma democracia política, com direitos individuais garantidos e funcionamento das instituições democráticas, defronta-se com a prevalência e reprodução de práticas como o clientelismo e o particularismo. Cabe destacar que no marco da literatura de transição e consolidação que trabalha com a idéia de poliarquia, o clientelismo e o particularismo passam a ser vistos não mais como processos históricos característicos da formação política na maioria dos países da América Latina, mas sim com um certo estranhamento, como anomalia, defeito, patologia ao funcionamento das democracias nestes países.

É nesse aspecto que sugerimos anteriormente uma analogia entre a artificialidade daidéiade que a transição estaria consolidada com a implementação, na América Latina, da poliarquia nos moldes dos países desenvolvidos ocidentais, e a artificialidade e ficção da implementação do liberalismo político em uma sociedade patrimonial, como apontado por Faoro (1993). As variáveis políticas disponíveis no modelo das poliarquias não fornecem, ademais, instrumental analítico para lidar com fenômenos como o clientelismo, patrimonialismo, mandonismo, etc. 0 que gerou, posteriormente, uma autocrítica por parte de um dos referentes da transitologia, ao apontar que a definição de poliarquia tem pouca capacidade para entender a realidade das democracias latino-americanas, ao não levar em conta, dentre outras coisas, as regras informais, tais com o clientelismo (0’DONNELL, 1997, p. 42-43).

Uma discussão atenta aos fundamentos históricos das práticas e relações que levam ao ofuscamento dos limites entre público e privado, no caso brasileiro, é feita por Carvalho (1997), que propõe uma delimitação teórica de conceitos como coronelismo, clientelismo e mandonismo baseada nos limites históricos e geográficos de cada conceito. 0 tratamento histórico destes fenômenos fornece uma contribuição para a sua compreensão no contexto político atual, fornecendo elementos adicionais às variáveis essencialmente políticas presentes no modelo da poliarquia. Permite também uma mudança de enfoque para o tratamento destes temas: de elementos alheios à democracia, anomalias e patologias que convivem com os procedimentos democráticos formais, a processos historicamente 
inscritos na formação política e social dos países latino-americanos, presentes e determinantes na construção das instituições políticas formais.

Dentre os processos tratados por Carvalho (1997) está o coronelismo, cuja delimitação remete à obra de Nunes Leal "Coronelismo, Enxada e Voto" (1948). Carvalho define coronelismo como:

Um sistema político nacional, baseado em barganhas entre 0 governo e os coronéis. 0 governo estadual garante, para baixo, o poder do coronel sobre seus dependentes e seus rivais, sobretudo cedendo-lhe o controle dos cargos públicos, desde o delegado de polícia até a professora primária. 0 coronel hipoteca seu apoio ao governo, sobretudo na forma de votos. Para cima, os governadores dão seu apoio ao presidente da República em troca do reconhecimento deste de seu domínio no estado (CARVALHO, 1997, p. 5).

A existência desta rede é historicamente datada, indo de 1889, quando da implantação da política dos governadores pelo presidente Campos Sales em substituição da indicação, pelo governo federal, do Presidente de Estado, passando este a ser eleito pelo jogo de oligarquias locais; até o fim desta forma de federalismo com a implantação da figura do interventor por Getúlio Vargas. Essa delimitação histórica diferencia o coronelismo do mandonismo e do clientelismo. 0 mandonismo implica na existência local de estruturas oligárquicas e personalizadas de poder, nas que há domínio pessoal e arbitrário por parte do mandão - que pode ou não ser um coronel. Esta é uma característica da política local, mas não um sistema como o coronelismo. Pode-se dizer que o coronelismo é um tipo de mandonismo restrito a uma fase histórica específica. 0 clientelismo, diferentemente do mandonismo, é uma troca hierárquica que implica necessariamente em uma concessão de benefício públicos. Ou seja, a relação que caracteriza o clientelismo é entre atores políticos. A utilização corrente do termo coronelismo para se referir a relações entre atores políticos urbanos, oligarquias municipais e mesmo relações rurais nas quais não está mais presente a figura do coronel deveria ser substituída, na concepção do autor, pelo termo "clientelismo".

Após essa breve descrição dos conceitos recorrentemente presentes na literatura sobre transições democráticas e democratização podemos apresentar nossa segunda crítica ao conceito minimalista de democracia procedimental, tal como o presente na noção de poliarquia, utilizado por parte dessa literatura. Se, por um lado, práticas como o clientelismo são entendidas como problemáticas do ponto de vista do funcionamento das instituições, por outro lado, as ferramentas 
analíticas utilizadas para avaliar tal funcionamento muitas vezes não permitem a abordagem das condições que possibilitam a reprodução daquelas práticas. Por condições que possibilitam a reprodução de práticos com o clientelismo, mandonismo, patronagem, etc., estamo-nos referindo à pobreza e desigualdade social, categorias ausentes no modelo da poliarquia, uma vez que este realiza um descolamento entre condições sócio-econômicas e funcionamento das instituições políticas:

A evidência simplesmente não sustenta a hipótese de que um alto nível de desenvolvimento sócio-econômico é tanto uma condição necessária como suficiente para uma política competitiva, nem a hipótese inversa de que a política competitiva é tanto uma conclusão necessária como suficiente para um alto nível de desenvolvimento sócio-econômico (DAHL apud REIS; CHEIBUB, 1993, p. 254-255).

Cabe observar que também a literatura de transição considera os dois processos como passíveis de ocorrer em momentos separados, contudo, colocando a democracia política como "o caminho mais viável - senão o único - para se prosseguir com a colocação de perguntas que enfoquem a ampliação da democracia em planos sociais e econômicos" (0'DONNELL, 1986, p. 79)4 .

Elucidemos 0 argumento exposto acima através de dois exemplos. 0 primeiro, que trabalha na concepção minimalista de democracia, qualificando sistemas políticos onde há a presença de eleições livres, mas ausência de garantias de direitos constitucionais como democracias iliberais (SMITH; ZIEGLER, 2008). 0 segundo, que questiona a validade e permanência da noção de poliarquia quando contrastada com uma problematização de indicadores de pobreza e desigualdade. De acordo com a primeira análise, a constatação de que nos processos de transição levados a cabo nas últimas décadas em toda a América Latina prevaleceram as democracias iliberais - nas quais os direitos constitucionais não foram respeitados - é contrastada com uma série de variáveis sócio-políticas e econômicas, como

\footnotetext{
${ }^{4}$ Cabem, nesse ponto, duas ressalvas à defesa que as teorias de transição democrática fazem da democracia política e da livre competição eleitoral como meta final. Em primeiro lugar, há que recordar o contexto de restrição de direitos políticos durante os regimes autoritários e a necessidade percebida como primordial de restabelecer-las no momento em que as obras foram escritas. Em segundo lugar, uma das preocupações centrais - e daí a importância dada aos pactos de transição entre elites civil e militar - era com a volta dos militares e do regime autoritário nas situações em que estes avaliassem que poderiam perder o controle sobre o processo, ou não ver atendidas suas condições, como foi o caso da transição na Bolívia e na Argentina antes de 1976.
} 
eleições presidenciais, hiperinflação, "levante social", etc. Contudo a concepção de democracia restrita aos critérios de eleições livres e garantia dos direitos constitucionais não permite à análise uma consideração dos possíveis ganhos de cada país referente, por exemplo, ao aumento da participação política. Em oposição, os autores chegam a conclusões gerais sobre a correlação entre determinadas variáveis, analisadas superficialmente, e a presença do modelo que seria o ideal: eleições livres + respeito aos direitos constitucionais. Considerações sobre como esses dois critérios ideais são passíveis de conviver juntamente com práticas clientelistas em democracias liberais também estão à margem da análise.

0 trabalho de Reis e Cheibub (1993), por outro lado, aborda diretamente os problemas sociais - notadamente os níveis de pobreza e de desigualdade crescentes no primeiro governo pós-transição - como limitações à consolidação da democracia no Brasil. Os autores apontam que: "quando a desigualdade social atinge um nível crítico passa a constituir uma ameaça ao regime porque aliena do jogo político vastas camadas da população" (REIS; CHEIBUB, 1993, p. 237). Com efeito, a população vivendo abaixo da linha da pobreza não tem incentivos para fazer parte da sociedade civil ou para participar da esfera política. Essa alienação decorrente da desigualdade social tem efeitos negativos para a consolidação da democracia:

0 fracasso em assegurar a lealdade política dos desfavorecidos representaria uma ameaça à democracia, pois possibilitaria a institucionalização de alguma forma de democracia altamente restritiva. Portanto, o que deve ser temido não é uma mobilização popular imediata contra a ordem constitucional, mas a cristalização de um sistema político restritivo que viria a sancionar o apartheid social de facto existente (REIS; CHEIBUB, 1993, p. 251).

Em oposição ao argumento da literatura sobre estabilidade democrática de viés conservador (HUNTINGTON, 1975), a consideração das questões sociais entra aqui não como uma preocupação com a manutenção das instituições democráticas em face da ameaça de mobilização popular, mas sim como um descrédito e falta de interesse que poderia levar a uma falta de legitimidade do sistema democrático. Falta de legitimidade uma vez que ele estaria sancionando um apartheid social ao se acreditar que poderia funcionar bem, independentemente das condições sociais existentes.

As considerações sobre insatisfação com a democracia representativa, por parte dos setores sociais destituídos, levam-nos a nossa última crítica às teorias 
de transição democrática que trabalham com um conceito procedimental de poliarquia como meta da consolidação democrática. Tal concepção de democracia, ao destacar a competição eleitoral livre e o funcionamento adequado das instituições formais como critérios determinantes da consolidação, deixa de considerar outras formas de participação política que extrapolam a participação via canal eleitoral (AVELAR, 2004). Em outras palavras, o entendimento da democracia, apenas como o procedimento que garante a representação política, implica na desconsideração da participação popular por meio de ações coletivas e ações diretas de protesto como processos também inerentes à democracia.

Como aponta Vitullo (2006), em crítica às teorias de transição e consolidação, a literatura de viés mais conservador e elitista - na qual esta estaria inserida ao destacar sobremaneira o papel dos pactos entre elites como elemento essencial das transições democráticas ${ }^{5}$-, tende a considerar a participação política direta (com mobilizações, demonstrações, greves, etc.) como causadora de instabilidade democrática e ameaçadora à tão cara "governabilidade". Em oposição, o tratamento insuficiente dado às ações dos movimentos sociais e outros atores coletivos organizados como agentes de ampliação e "democratização da democracia" é apontado por Vitullo (2006) como uma das maiores deficiências da Ciência Política, que não pode ficar alheia a estes processos ou considerá-los como elementos à parte do que é concebido como democracia:

Certa capacidade disruptiva resulta necessária, não apenas para enriquecer 0 debate na esfera pública, para chamar atenção da maioria superando 0 controle midiático, a opacidade e a manipulação comunicativa, e um estreito conceito de ordem pública, senão do ponto de vista do pluralismo, para incluir alternativas excluídas do leque das consideradas possíveis pelo consenso hegemônico (MÁiZ apud VITULLO, 2006, p. 11).

Com essa última observação, podemos concluir esta sessão voltando ao que nos parece ser uma contradição presente nas análises sobre transições democráticas e democratização que questionam a validade do conceito de poliarquia para compreender os processos existentes na América Latina, mas que não rompem

\footnotetext{
${ }^{5}$ A mesma crítica é feita por Avritzer (2002) ao apontar para o caráter elitista da literatura sobre transição democrática que dá um papel desproporcionalmente marginal à participação da sociedade civil nos processos de transição. 0 autor propõe, em contrapartida, uma concepção segundo a qual a emergência da democracia política estaria ligada à "formação de um espaço público onde os cidadãos possam participar como iguais e, discutindo sobre projetos coletivos para a sociedade, possam guiar o processo formal de decisão política" (AVRITZER, 2002, p. 5).
} 
com a concepção minimalista de democracia representativa. Essa contradição pode ser percebida em 0'Donnell (1997), que se preocupa com o fato de que uma má qualidade de vida social possa aparecer juntamente e conviver com vários tipos de poliarquias; o que o leva a argumentar que o conceito de poliarquia deve então ser trabalhado e tipificado para compreender melhor as diferenças e alternativas existentes em países como os da América Latina.

Contudo, a permanência da poliarquia como limite epistemológico impede a visualização de todas as ações realizadas por canais não institucionais (ou seja, além da participação via processo eleitoral) que podem pressionar por uma mudança na qualidade da vida social. Se, de um lado, há uma insatisfação com a não-adequação das democracias latino-americanas aos critérios desejáveis da poliarquia - ou antes, há uma adequação aos critérios formais, mas esta vem acompanhada por regras informais como o clientelismo -; de outro lado, essa inadequação é vista com grande pessimismo na medida em que a única saída que se vislumbra é por meio da representação política, marcada por uma delegação unilateral (0’DONNELL, 1993). Nesse sentido, a análise é pessimista e determinista na medida em que o referencial teórico não fornece ferramentas analíticas para conceber outras formas de ação política possíveis. Ações estas também agentes e motoras de mudança na vida social, tais como as ações de movimentos sociais, as reivindicações por meio de ações coletivas diretas e outras formas de ação disruptivas que "fornecem alternativas excluídas do leque das consideradas possíveis pelo consenso hegemônico" (VITULLO, 2006).

\section{Pobreza, PARTicipaÇão Política E DEMOCRACIA}

Como assinalado no final da última sessão, outro problema de se trabalhar no marco da concepção minimalista de democracia é a restrição do que se entende por política e por participação. Essa deficiência guarda relação com o problema mais amplo de insulamento em relação aos processos de pobreza e desigualdade social como determinantes da democracia e da democratização. Com efeito, assim como é possível construir um diagnóstico positivo da democracia, olhando apenas para o funcionamento das instituições no sistema político formal e ignorando outros elementos como pobreza, desigualdade social - que por sua vez garantem a reprodução de processos de clientelismo, mandonismo patrimonialismo -; também é possível avaliar a maior ou menor eficácia da democracia deixando à margem os processos participativos dos setores populares organizados, que no mais das vezes são feitos por canais extra-intitucionais. 
A seguir discutiremos algumas contribuições da literatura sobre democracia participativa que apontam críticas à concepção minimalista de democracia. 0 faremos à luz do contexto latino-americano pós-década de 1990, levando em consideração os processos de implementação de reformas estruturais no marco do neoliberalismo.

Apesar das diferenças de profundidade e extensão na implementação de reformas estruturais nos vários países latino-americanos, cabe observar que elas resultaram - pelo menos em curto e médio prazo - no aumento das desigualdades de renda e no aumento das taxas de desemprego. Auyero (2000) discute esse processo no contexto argentino e ressalta o forte impacto que as políticas de privatização, levadas a cabo no governo Menem (1989-1998), tiveram nos níveis de emprego - a taxa de desemprego sobe de 5\% em 1974 para 18.6\% em 1995. Em uma análise mais abrangente do subcontinente, Vilas (2004) aponta para 0 aumento da pobreza e da polarização na distribuição de renda em vários países da América Latina, em fins da década de 80 e início da década de 90. Esse aumento crescente da pobreza e desigualdade é problematizado por Vilas (2004) e por Auyero (2000) em diferentes aspectos. 0 último se preocupa em entender quais os meios utilizados pelas pessoas para sobreviver a uma situação de desemprego e renda inexistente, e o primeiro aponta para a pobreza crescente como fator impeditivo da existência de uma cidadania de fato, que seria uma condição necessária à democracia.

Apesar de crítico à noção tradicional de democracia - como discutiremos mais adiante - Vilas (2004) assinala que o aprofundamento das desigualdades sociais e da pobreza é incompatível mesmo como princípio de cidadania formulado pela teoria política liberal anglo-saxã:

Como quer que seja definida (mesmo em seu minimalista, procedimental sentido), a democracia é um regime inclusivo. Envolve a participação de todos os cidadãos na polis e é vista como pertencente a todos [...]. Mas a polis pode dificilmente ser considerada como pertencente a todos quando 0 princípio de cidadania (como um síntese dos direitos de participação e obrigação de contribuição) [...] devem coexistir com as desigualdades profundas e crescentes da maioria dos países (VILAS, 2004, p. 21).

Ligada à noção de cidadania está outra problemática levantada pelo autor na análise da América Latina, nomeadamente a da relação entre pobreza e participação política - entendida como "a participação em processos e instituições 
nos quais decisões relevantes são tomadas sobre a vida, sobre bem-estar, sobre 0 que as pessoas consideram importante" (VILAS, 2004, p. 20). Cumpre ressaltar que determinadas formas de participação política, como os vários repertórios de ação coletiva dos movimentos sociais, são, na concepção do autor, formas distintas de conceitualizar e praticar a cidadania.

Importa para nossa discussão explicitar algumas das formulações sobre 0 conceito de participação política, uma vez que tal conceito é chave para a noção de democracia e varia conforme a definição ou concepção do que é considerado como parte do processo democrático. Alessandro Pizzorno (1975) se preocupa em explicar as causas e as condições da participação política. Ele analisa dois modelos distintos explicativos da participação política: o "modelo da consciência de classe", cuja hipótese principal é a de que quanto maior a consciência de classe maior a participação política, a qual, por sua vez, aumenta a consciência de classe; e 0 "modelo da centralidade", segundo o qual a participação política é maior quanto maior for a posição social de um indivíduo, e, portanto, ela pode ser entendida como expressão do pertencimento a determinado grupo social.

A partir desses modelos, Pizzorno constrói uma tipificação da participação política que, segundo ele, pode ocorrer de quatro formas distintas. Existem aquelas em que a solidariedade política prevalece e aquelas em que a solidariedade privada prevalece. Dentre as primeiras estão: (a) profissionalismo político (tipo de ação inserida no sistema estatal e definida pelo fato de se viver da política) e (b) movimento social (cuja ação é extra-estatal, ou seja, encontra-se fora da estrutura dos canais tradicionais que conduzem ao Estado). As formas de participação política nas quais a solidariedade privada prevalece são: (c) participação civil na política, como por exemplo, a adesão a partidos de opinião, o pertencimento a associações voluntárias integrantes do sistema e a grupos corporativos de interesse e outros similares (ações inseridas na estrutura do sistema estatal); e (d) subcultura política, que pode ser entendida como uma forma de agrupamento e organização de indivíduos que se sentem em condições de inferioridade em relação ao sistema de valores prevalecentes na sociedade e se identificam de acordo com determinado atributo comum - que seria supostamente a origem de tal inferioridade. As subculturas participariam politicamente utilizando o peso político de seus atributos de inferioridade civil, como forma de atingir objetivos particulares (privados), diferindo da participação civil na medida em que estão excluídas dos canais normais que acedem às instituições estatais (PIZZORNO, 1975). 
Avelar (2004), apresenta uma diferente tipificação das formas de participação política. Segundo ela, essa participação pode ocorrer de três formas possíveis. A primeira delas é por meio do canal eleitoral, o qual "compreende as atividades nos partidos que são as instituições de ligação entre a sociedade e 0 Estado" (AVELAR, 2004, p. 226). Dentre as formas de participação política estão: 0 ato de votar ou de se candidatar, filiar-se a um partido político, arrecadar ou fornecer fundos para campanhas eleitorais. A segunda forma de participação política é pelos canais corporativos, que podem ser entendidos como instâncias intermediárias de organização de categorias e associações de classe, como por exemplo, os sindicatos, que buscam defender seus interesses no âmbito do sistema estatal. As atividades corporativas podem ser consideradas, então, como formas de intermediação de interesses entre Estado e sociedade. Essa forma de participação se aproxima do que Pizzorno chama de "participação civil". A terceira forma possível de participação política é via canal organizacional, que consiste em "formas não-institucionalizadas de organização coletiva como os movimentos sociais, as subculturas políticas, etc" (AVELAR, 2004, p. 225). As atividades compreendidas por esta forma de participação são, por exemplo, movimentos sociais que se articulam geralmente para contestar valores correntes de uma sociedade. A eficácia deste tipo de participação estaria diretamente relacionada ao grau de cooperação entre os membros de uma organização e ao grau de identificação de interesses comuns entre eles. Observe-se que Avelar (2004) coloca em uma mesma categoria as duas formas de participação que Pizzorno havia considerado como ações levadas a cabo fora do sistema estatal - movimentos sociais e subculturas políticas ${ }^{6}$.

\footnotetext{
${ }^{6}$ Cabe aqui uma ressalva no tocante às tentativas de classificação das diferentes formas de participação política e de estabelecimento de uma correspondência entre determinadas formas e determinados atores. 0 exercício da classificação pode ter utilidadecomo ferramenta teórica para análise de processos mais amplos e complexos. Contudo, a compreensão da participação, somente a partir das categorias delimitadas, pode levar a um engessamento do campo de análise se o pesquisador não se atenta para as contradições entre a observação empírica e o modelo teórico. Outro problema é a utilização da classificação para abarcar as formas de participação possíveis de determinado ator político. Nesse caso, a utilização do modelo pode levar a uma visão equivocada e superficial da ação política de determinados atores. Por exemplo, a compreensão de um movimento social ou se uma organização sindical, a partir do estabelecimento de uma correspondência com suas formas de participação política "características" (via canal organizacional e canal corporativo respectivamente), pode levar a uma interpretação incompleta dos campos de ação destes atores políticos. Nesse sentido, as classificações devem ser utilizadas para auxiliar na compreensão de diferentes formas possíveis de participação, que podem ser levadas a cabo por um mesmo ator, inclusive de forma simultânea. E não para enquadrar cada ator em cada categoria, de acordo com cada forma de participação, o que não contribuiria para a compreensão e interpretação de sua ação política.
} 
A participação não convencional, via canal organizacional, foi amplamente discutida pela literatura sobre movimentos sociais e ações coletivas. Uma das formas pelas quais esta participação política tem sido trabalhada é por meio do conceito de "repertório". Repertórios são "formas culturalmente codificadas por meio das quais as pessoas interagem em políticas de contestação" (MCADAM; TARROW; TILLY, 2001, p. 16). Seu surgimento e sua forma seriam resultado de três elementos: organização da vida social cotidiana, experiência cumulativa em beligerância, e intervenção do regime (TILLY, 2006). Sobre este ultimo elemento, cumpre destacar que a relação entre protesto e sistema político formal é, no mais das vezes, conflituosa. Como aponta Tilly (2006), os governos em todo o mundo geralmente resistem em garantir o direito legal às demonstrações como tais. $\mathrm{Na}$ maioria das vezes está presente na Constituição ou legislações correspondentes apenas o direito de se associar, formar sindicatos e fazer greves.

Outro conceito relevante para a discussão sobre participação política via canal organizacional é o de oportunidades políticas. Oportunidades políticas são "dimensões consistentes - mas não sempre formais ou permanentes - do ambiente político que fornecem incentivos para a ação coletiva ao afetarem as expectativas das pessoas quanto ao sucesso o ao fracasso" (TARROW, 2009, p. 105). De acordo com a definição, essas dimensões seriam elementos externos ao grupo, podendo ser mais ou menos formais e permanentes, e afetando as expectativas das pessoas com respeito ao possível êxito de uma ação coletiva. Maior ou menor abertura e tolerância de determinado governo em relação à participação política não-convencional seria um exemplo de oportunidade política para ação dos atores coletivos.

Tendo em vista essas formulações conceituais, cabe assinalar que quando Vilas (2004) discute a relação entre participação política e desigualdade ele apresenta dois elementos relevantes para a análise, que também aparecem em trabalhos de outros autores (AVRITZER; COSTA, 2004; DAGNINO, 2006). 0 primeiro deles é uma crítica à incapacidade das abordagens em torno da democracia representativa - e das construções conceituais cujo critério principal para a definição de democracia é o de representação eleitoral - de se relacionar com a participação política levada a cabo via canal organizacional (AVELAR, 2004) ou por fora do sistema estatal (PIZZORNO, 1975). A perspectiva que dá primazia à democracia representativa se relaciona, de forma geralmente inconfortável, com a participação social na medida em que sua rigidez política e institucional tende a relegar os movimentos sociais à esfera do protesto social e da pressão por fora do 
sistema político. Contudo, de acordo com o autor, a legitimidade da democracia representativa fica comprometida ao não processar e incluir em suas agendas as demandas dos movimentos sociais, contribuindo também para reforçar a marginalidade institucional destes movimentos (VILAS, 2004).

Cabe ressalvar, todavia, que, quando se olha para os indivíduos que participam politicamente, a relação entre participação convencional e nãoconvencional não é excludente, mas antes complementar. Com efeito, como demonstra pesquisa realizada em Montevidéu, Santiago e Porto Alegre (B0RBA; RIBEIR0, 2010), a participação em uma das modalidades constitui o maior preditor para a participação em outra. Ademais, esta variável apresentou maior poder explicativo - em comparação com variáveis socioeconômicas e atitudinais - para explicar a própria participação política convencional e não convencional dos indivíduos.

0 segundo elemento de destaque, na análise de Vilas (2004), é a argumento de que 0 aumento das desigualdades sociais e da pobreza tem impactos negativos na possibilidade de participação política das classes excluídas e no acesso destas às esferas de tomada de decisão. 0 que seria 0 resultado do processo histórico de constituição do Estado e sua relação com as sociedades nos países latinoamericanos. A dificuldade de acesso dos grupos desfavorecidos às instâncias de tomada de decisão, ao mesmo tempo em que determinados setores têm influência determinante nas decisões políticas - notadamente via canal corporativo (AVELAR, 2004), denota uma desigualdade referente à possibilidade de participação política que reflete uma desigualdade sócio-econômica. Outro problema assinalado pelo autor é o fato de que não obstante estejam surgindo novos espaços de participação política popular, as esferas nas quais as decisões são tomadas, de fato, estão se deslocando destes espaços para níveis mais restritos ou mesmo internacionais processo que se acentua com a globalização dos mercados e ação dos organismos financeiros multilaterais, que impõem aos governos condicionalidades em termos de políticas econômicas e sociais.

A esfera pública ${ }^{7}$, como espaço de comunicação e ação dos diferentes grupos fora do escopo do Estado, também é apontada por Avritzer e Costa (2004) como elemento constitutivo da democracia. Nesse sentido, estes autores também são críticos à concepção minimalista de democracia como construção institucional,

\footnotetext{
7 "Contexto de relações difuso no qual se concretizam e se condensam intercâmbios comunicativos gerados em diferentes campos da vida social” (AVRITZER; COSTA, 2004, p. 722)
} 
tal como se apresenta nos trabalhos de transição democrática. Eles argumentam que a vigência da democracia implica a "incorporação de valores democráticos nas práticas cotidianas" (AVRITZER; COSTA, 2004, p. 705) e, portanto, não se pode falar em consolidação democrática tomando-se em conta apenas a construção das instituições. A democratização das relações no escopo da sociedade civil é um processo indispensável para a construção de uma verdadeira democracia, sendo os espaços públicos ${ }^{8}$ um dos lugares centrais de participação da sociedade civil. Tais espaços, por sua vez, poderiam levar a uma ampliação da democracia, uma vez que contribuem para a realização de formas críticas de comunicação, ou para a problematização de temas antes excluídos.

Os processos de ajustes estruturais neoliberais na América Latina, ao longo da década de 1990, tiveram também impacto na esfera pública (AVRITZER; COSTA, 2004) no escopo daquilo que Dagnino, Olvera e Panfichi (2006) chamaram de confluência perversa de dois projetos políticos (neoliberal e participativo) com lógicas distintas, mas que utilizam a mesma gramática - participação, sociedade civil, cidadania, democracia -, todavia, com significados distintos?

Projetos políticos se referem a "conjuntos de crenças, interesses, concepções de mundo, representações do que deve ser a vida em sociedade, que orientam a ação política dos diferentes sujeitos" (DAGNINO; OLVERA; PANFICHI,

8 "Os espaços públicos seriam aquelas instâncias deliberativas que permitem o reconhecimento e dão voz a novos atores e temas; que não são monopolizados por algum ator social ou político ou pelo próprio Estado, mas são heterogêneos, ou seja, refletem a pluralidade social e política" (DAGNINO; OLVERA; PANFICHI, 2006, p. 23-24).

${ }^{9}$ Alguns dos conceitos em disputa pelos projetos neoliberal e democrático participativo seriam os de cidadania, sociedade civil, participação, democracia e política. De acordo com Dagnino, Olvera e Panfichi (2004 e 2006), no projeto político neolibereal o significado de cidadania teria se deslocado de uma noção de cidadania ampliada, de direito a ter direitos e criação de novos direitos para os excluídos, para uma cidadania relacionada à idéia de solidariedade para com os pobres, ou caridade. No mesmo sentido, o conceito de participação também passa a ter uma perspectiva privatista e individualista, em substituição à idéia de participação social, coletiva, através da constituição de espaços públicos. E o conceito de sociedade civil se desloca de uma noção mais ampla e inclusiva de espaço para representações de interesses heterogêneos da sociedade, como por exemplo, através de movimentos sociais, para uma noção restrita e seletiva da participação de ONGs, fundações empresariais "filantrópicas", e outras organizações do "terceiro setor" vistas como parceiras ou complementares às funções do Estado. Quanto ao significado de democracia e política, pode-se dizer que no projeto neoliberal esses termos remetem a noções mais minimalistas, de representação no sistema político formal, ao passo que o projeto democrático-participativo concebe noções mais ampliadas de democracia e política, com participação social e sociabilidade. 
2006, p. 38). Na noção de projeto político estaria implícita, segundo os autores, uma idéia de intencionalidade e do papel do sujeito como agência, bem como a afirmação da política como terreno estruturado por escolhas, expressas nas ações e orientadas por estruturas cognitivas dos indivíduos. Nesse sentido, Dagnino, Olvera e Panfichi (2006) apontam que a noção de projeto político não se reduz a estratégias de atuação política, no sentido estrito, ou a formulações sistematizadas e abrangentes, como os projetos partidários, mas "expressam, veiculam e produzem significados que integram matrizes culturais mais amplas" (DAGNINO; OLVERA; PANFICHI, 2006, p. 39-40).

De acordo com estes autores, os projetos políticos seriam constituídos no contexto e a partir de determinada cultura política ${ }^{10}$, a qual eles poderiam, não obstante, alterar em alguma medida. Nesse sentido, os movimentos sociais como atores coletivos são portadores de determinados projetos políticos, o que se aproxima da noção utilizada por Alvarez, Dagnino e Escobar (2000) em trabalho anterior: política cultural ${ }^{11}$.

A política cultural posta em prática pelos movimentos sociais, ao contestar e dar novo significado ao que conta como político e quem - além da "elite democrática" - define as regras do jogo político, pode ser crucial, sustentamos, para promover culturas políticas alternativas e, potencialmente, ampliar e aprofundar a democracia na América Latina (ALVAREZ; DAGNINO; ESCOBAR, 2000, p. 31).

Nesse sentido, os movimentos sociais, ao levar a cabo políticas culturais que podem conformar projetos políticos mais amplos, estariam, no mais das vezes, buscando desafiar ou desestabilizar a cultura política dominante. Por meio de suas ações, esses movimentos sociais podem levar à criação de arenas públicas não-governamentais ou extra-institucionais que permitam a participação política de grupos subalternos ou excluídos - notadamente no processo de aumento das assimetrias e pobreza da década de 1990 (ALVAREZ; DAGNINO; ESCOBAR, 2000). 0 que significa que a defesa de determinados projetos políticos ou políticas culturais implica em determinadas formas de ação política por parte dos movimentos sociais, tais como a criação de espaços públicos participativos como instâncias

10 "A construção social particular em cada sociedade do que conta como político" (ALVAREZ; DAGNINO; ESCOBAR, 2000, p. 25). Para uma discussão mais aprofundada dos conceitos de cultura política e projeto político ver Penna (2008).

${ }^{11}$ Processo pelo qual o cultural se torna fato político (ALVAREZ, DAGNINO E ESCOBAR, 2000, p. 17). 
de participação política fora dos canais tradicionais (eleitoral e corporativo). Um exemplo seriam as assembléias de bairro em várias cidades argentinas e a Asemblea Popular de los Pueblos de Oaxaca no México.

Pode-se dizer que, de modo geral os movimentos sociais têm como orientação política e cultural o projeto político participativo, o que implica determinadas concepções sobre o significado de democracia, de política, de cidadania e de participação; algumas das quais discutidas em nota anteriormente. Em se tratando da concepção de democracia importa observar que aparece aqui a mesma crítica à democracia considerada unicamente em seu aspecto eleitoral, presente nas análises de Vilas (2004) e Avritzer e Costa (2004). Com efeito, a noção de democracia no escopo do projeto político participativo é uma:

[...] cujo fundamento é a ampliação do conceito de política mediante a participação cidadã e a deliberação nos espaços públicos, do que deriva uma noção de democracia como um sistema articulado de instâncias de intervenção dos cidadãos nas decisões que thes concernem e na vigilância do exercício do governo (DAGNINO; OLVERA; PANFICHI, 2006, p. 17).

Democracia seria, de acordo com Dagnino, Olvera e Panfichi (2006) um conceito em disputa, no marco dos projetos neoliberais e participativos: "é possível afirmar que a disputa ao redor da democracia se apresenta, na maioria dos países, como um embate [...] entre os projetos neoliberal e democrático participativo" (DAGNINO; OLVERA; PANFICHI, 2006, p. 43). Mas, o projeto participativo de democracia aparece também em oposição ao conceito tradicional de democracia:

0 debate contemporâneo sobre a democracia emerge como resposta às características elitistas e excludentes das democracias eleitorais e às teorias que fundem a compreensão limitada e limitante dessas democracias. Com efeito, a teoria democrática convencional [...] limita o conceito de política à luta pelo poder entendido como a obtenção da autorização e da representação por meio das eleições (DAGNINO; OLVERA; PANFICHI, 2006, p. 17).

Nesse sentido, cabe ressaltar que nos autores aqui analisados, e cujas análises apresentam uma crítica direcionada ao conceito tradicional de democracia, o ponto convergente é o destaque dado à participação política via canal organizacional (AVELAR, 2004). Mais especificamente ao argumento de que essa forma e espaço de participação política são dimensões fundamentais da democracia, e que, não obstante, estão excluídas das concepções e definições tradicionais de democracia. Tais concepções são, pois, criticadas por conceber 
como determinante apenas uma das dimensões da participação política, qual seja: a levada a cabo via canal eleitoral. A crítica se dirige principalmente ao fato de que tal concepção de democracia, na medida em que é a concepção dominante, contribui para uma marginalização das ações dos movimentos sociais ou outras organizações ao campo do protesto e da pressão (VILLAS, 2004); e ao fato de que a não consideração dos processos levados a cabo nas esferas públicas resulta na não criação de foros deliberativos que possam tornar vinculantes as decisões tomadas no escopo da sociedade civil (AVRITZER; COSTA, 2004).

\section{ConClusões}

0 trabalho tentou mostrar como uma forma específica de entender a democracia e a política - minimalista e procedimental - tem implicações para a maneira como pensamos e analisamos a realidade política latino-americana. $\mathrm{Na}$ primeira sessão destacamos como a concepção de democracia, presente nos estudos sobre transição democrática, pode passar à margem de aspectos fundamentais para a democratização - no campo social, como os problemas de pobreza, exclusão social e desigualdade, e no campo político, como o clintelismo, mandonismo, patrimonialismo, etc. A compreensão destes elementos como deslocados da idéia mais ampla de democracia, restrita à noção procedimental, produz análises superficiais da realidade latino-americana. A produção recorrente de análises e conclusões sobre a democracia nos países latino-americanos, que olha apenas para o campo dos procedimentos e instituições formais, levam também à redução da relevância e da centralidade destes problemas, uma vez que se considera que a democracia pode existir apesar e independentemente deles.

$\mathrm{Na}$ segunda sessão problematizamos a limitação da perspectiva minimalista de democracia, no que diz respeito à participação política, o que está relacionado com a própria noção restrita de política. A compreensão de política, como aquilo que ocorre no âmbito do sistema político formal, e a noção de participação política, como participação eleitoral, têm implicações tanto para a análise como também para a legitimação ou não da própria ação política. No que tange à análise, cabe destacar que com essa concepção de participação política se limita o escopo dos trabalhos que se propõem a estudar o funcionamento da democracia e a democratização. Ao não reconhecer como parte integrante da democracia a participação política, que ocorre além do voto, esses estudos deixam de lado processos relevantes para a própria construção da democracia. 
Cabe esclarecer que estes processos de mobilização ou de participação política, via canal organizacional, consideram-se importantes não só na medida em que eles têm impacto no sistema eleitoral ou na medida em que resultam na construção de espaços políticos ou instituições regulamentadas pelo Estado e cujas decisões sejam legalmente vinculantes. Diferentemente do que aponta Olvera (2009) sobre os efeitos de mobilizações "anti-sistêmicas", derrotadas no México (EZLN e APP0 $)^{12}$, que não puderam contribuir para aprofundar a democracia e a cidadania - uma vez que não apresentaram um programa propositivo e não alteraram a configuração política institucional -, ressalta-se aqui a necessidade de compreender essas experiências como construtivas do processo democrático. Embora não tenham representado mudanças imediatas nas regras do jogo democrático formal, essas experiências têm implicações na forma em que seus participantes concebem a política e a participação política.

Elas podem levar, como assinala Recondo (2007) para o caso de Oaxaca, à formação de uma "cidadania mais crítica e parcialmente liberada dos compromissos clientelares". Ou ainda, como aponta Rossi (2008), no caso das assembléias de bairro argentinas que tiveram seu auge entre 2001 e 2002, podem levar a uma mudança na forma de conceber a política e a participação marcada pela interpretação de que "segue sendo imprescindível deixar de delegar aos representantes as decisões se o que se quer é evitar que volte a haver abusos no poder" (ROSSI, 2008, p. 83).

Não ver essas mobilizações como possibilidades democráticas é deixar de fora da análise elementos que são relevantes para a consolidação da democracia, na medida em que se impossibilita a visualização dos processos e experiências de onde vêm algumas das importantes transformações na cultura política (PENNA, 2008).

\section{REFERÊNCIAS}

ALVAREZ, Sônia; DAGNINO, Evelina; ESCOBAR, Arturo. 0 cultural e o político nos movimentos sociais latino-americanos. In: ALVAREZ, Sônia; DAGNINO, Evelina; ESCOBAR, Arturo (Org.). Cultura e política nos movimentos sociais LatinoAmericanos. Belo Horizonte: UFMG, 2000. p. 15-60. ${ }^{12}$ Ejército Zapatista de Liberación Nacional (EZLN) e Asemblea Popular de los Pueblos de Oaxaca
(APPO). 
AUYER0, Javier. Poor people's Politics: peronist survival networks and the legacy of Evita. Durham: Duke University Press, 2000.

AVELAR, Lúcia. Participação Política. In: AVELAR, Lúcia; CINTRA, Antônio Octávio. Sistema político brasileiro: uma introdução. Rio de Janeiro: Konrad-AdenauerStiftung, 2004.

AVRITZER, Leonardo. Democracy and the public space in Latin America. Princeton: Princeton University Press, 2002.

AVRITZER, Leonardo; COSTA, Sérgio. Teoria crítica, democracia e esfera pública: concepções e usos na América Latina. Dados, Rio de Janeiro, v. 47, n. 4, 2004.

BORBA, Julian; RIBEIR0, Ednaldo. Participação convencional e não convencional na América Latina. Revista Latinoamericana de Opinión Pública, Buenos Aires, v. $1,2010$.

CARVALHO, José Murilo de. Mandonismo, coronelismo, clientelismo: uma discussão conceitual. Dados, Rio de Janeiro, v. 40, n. 2, 1997.

DAGNINO, Evelina; OLVERA, Alberto; PANFICHI, Aldo. A disputa pela construção democrática na América Latina. São Paulo: Paz e Terra, 2006.

DAHL, Robert. Poliarquia: participação e oposição. São Paulo: Ed. USP, 1997.

FAORO, Raymundo. A aventura liberal numa ordem patrimonialista. Revista USP, São Paulo, n. 17, mar./abr./maio, 1993.

HUNTINGTON, Samuel P. A ordem política nas sociedades em mudança. São Paulo: Forense Universitária, 1975.

LINZ, Juan; STEPAN, Alfred. A transição e consolidação da democracia: a experiência do sul da Europa e da América do Sul. Rio de Janeiro: Paz e Terra, 1999 .

MCADAM, Doug; TARROW, Sidney; TILLY, Charles. Dynamics of contention. Cambridge: Cambridge Univ Press, 2001.

0’DONNELL, Guillermo. Acerca del estado, la democratización y algunos problemas conceptuales. Desarrollo Econômico, Local, v. 33, n. 130, 1993.

O'DONNELL, Guillermo. Illusions about consolidation. In: DIAMOND, L. et al. (Ed.). Consolidating the third wave democracies: themes and perspectives. Baltimore: The Johns Hopkins University Press, 1997. p. 40-58.

Contrapontos : autoritarismo e democratização. São Paulo: Vertice, 1986. 
O'DONNELL, Guillermo; SCHMITTER, Phillip; WHITEHEAD, Lawrence. Transições do regime autoritário: America Latina. São Paulo: Vértice, 1988.

OLVERA, Alberto. Sociedad civil, sociedad política y democracia en el México Contemporáneo. Revista de Estudos e Pesquisas sobre as Américas, Brasília, v. 3, n. 1, jan.jun. 2009.

PENNA, Camila. Cultura, cultura política e participação política: conceitos e concepções no debate sobre os movimentos sociais argentinos pós-2001. Revista Debates, Porto Alegre, 2008, n. 2, p. 70-103.

PIZZORNO, Alessandro. Introducción al estudio de la participación política. In: PIZZORNO, Alessandro; KAPLAN, Marcos; CASTELLS, Manuel. Participación y cambio social en la problemática contemporánea. Buenos Aires: Siap Planteos, 1975. p. 13-82.

RECOND0, David. Crónica de una muerte anunciada: el ocaso del partido de Estado en Oaxaca. Desacatos, Cidade do México, n. 24, p. 123-134, 2007.

REIS, Elisa; CHEIBUB, José. Pobreza, desigualdade e consolidação democrática. Dados, Rio de Janeiro, v. 36, n. 2, p. 233-260, 1993.

ROSSI, Federico. Aparición, auge y declinación de un movimiento social: las asambleas vecinales y populares de Buenos Aires 2001-2003. Revista Europea de Estudios Latinoamericanos y del Caribe, Amsterdã, n. 78, p. 67-88, 2008.

SHUMPETER, Joseph. Capitalism, socialism and democracy. New York: Harper e Row Publishers, 1975.

SMITH, Peter; ZIEGLER, Melissa. Liberal and iliberal democracy in Latin America. Latin American Politics and Society, Miami, v. 50, n. 1, 2008.

TARROW, Sidney. Poder em movimento: movimentos sociais e confronto político, Petrópolis: Vozes, 2009.

TILLY, Charles. Regimes and Repertoirs. Chicago: Chicago Press, 2006.

VIANA, Francisco Oliveira. Instituições políticas brasileiras. Brasília: Senado Federal, 1999.

VILAS, Carlos. Participation, inequality and the whereabouts of democracy. In: CHALMERS, D. et al. The new politics of inequality in Latin America: rethinking participation and representation. 0xford: Oxford University Press, 2004. p. 3-43.

VITULLO, Gabriel. As teorias da democratização frente às democracias latinoamericanas. Opinião Pública, Campinas, v. 12, p. 348-377, 2006. 